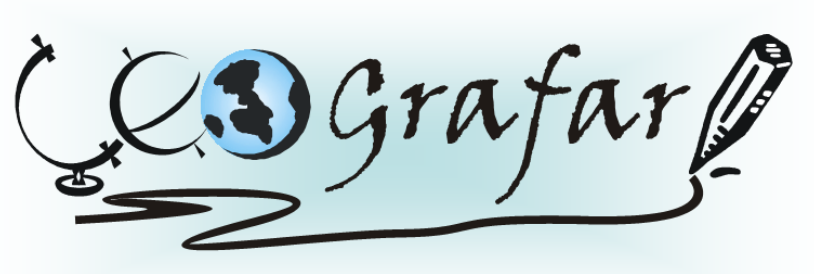

Revista Eletrônica do Programa de Pós-Graduação em Geografia - UFPR

\title{
A QUESTÃO ECOLÓGICA URBANA E A QUALIDADE AMBIENTAL URBANA
}

\section{THE URBAN ECOLOGICAL ISSUE AND THE URBAN ENVIRONMENTAL QUALITY}

\section{(Recebido em 02.09.2014; Aceito em: 22.07.2015)}

Laura Freire Estêvez Geógrafa, Dra. Universidade Federal do Paraná

Curitiba, PR, Brasil e-mail: laurafreire.geo@gmail.com

João Carlos Nucci Prof. Dr. do Departamento de Geografia Universidade Federal do Paraná

Curitiba, PR, Brasil e-mail: nucci@ufpr.br

\begin{abstract}
RESUMO
As alterações antrópicas são mais acentuadas em áreas urbanas. Além disso, as cidades tendem a apresentar problemas ambientais quando o planejamento urbano é inadequado. Para entender melhor os problemas ambientais e buscar soluções para eles é preciso estudar os limites e aptidões do ambiente urbano. A avaliação da qualidade ambiental urbana, que analisa aspectos biofísicos da cidade, pode cooperar nesse sentido. Assim, o objetivo do artigo foi realizar uma revisão de literatura dos estudos de qualidade ambiental urbana. Para tanto, buscou-se a bibliografia sobre a temática e realizou-se a sistematização dos estudos de qualidade ambiental urbana, dando enfoque aos critérios e parâmetro utilizados em sua análise. Constatou-se que a avaliação da qualidade ambiental urbana dá suporte à análise dos problemas ambientais ocorridos na cidade e pode contribuir para minimizar ou mesmo evitar os impactos ambientais urbanos.
\end{abstract}

Palavras-chave: Planejamento da Paisagem; ecossistema urbano; critérios e parâmetros. 


\begin{abstract}
Anthropogenic changes are more pronounced in urban areas. Additionally, the cities tend to have environmental problems when urban planning is inadequate. To better understand the environmental problems and seek solutions to them is necessary to study the limitations and capabilities of the urban environment. The assessment of urban environmental quality, which examines biophysical aspects of the city, may cooperate in this regard. Thus, the objective was to conduct a literature review of studies of urban environmental quality. To do so, we sought the bibliography on the subject and held the systematization of studies of urban environmental quality, focusing on criteria and parameters used in their analysis. It was found that the assessment of urban environmental quality supports the analysis of environmental problems occurring in the city and can help to minimize or even avoid urban environmental impacts.
\end{abstract}

Keywords: Ladscape Planning; urban ecosystem; criteria and parameters.

\title{
INTRODUÇÃO
}

Estudos sobre a qualidade ambiental urbana fornecem subsídios para entender os problemas ambientais decorrentes do acelerado processo de crescimento das cidades contemporâneas. Com base nas avaliações da qualidade ambiental urbana, é possível tomar decisões de planejamento e gestão que busquem diminuir ou mesmo evitar os impactos causados por ações antrópicas sobre o ambiente urbano.

A avaliação da qualidade ambiental urbana abordada neste trabalho baseiase no método desenvolvido por Nucci (1996, 2001, 2008), que é orientado pelos princípios do Planejamento da Paisagem, e que portanto, tem como arcabouço a perspectiva ecológica. Essa avaliação da qualidade ambiental se dá por meio da análise de critérios e seus parâmetros ${ }^{1}$. Assim, o presente artigo foi organizado de forma a apresentar uma revisão de literatura sobre a cidade dentro da perspectiva ecológica e sobre os estudos de qualidade ambiental, com enfoque aos estudos que vêm sendo elaborados no Brasil.

\footnotetext{
${ }^{1}$ Critério (atributo, característica, indicador) é aquilo que deve ser avaliado. E o parâmetro é a
} qualificação do critério: pode ser quantitativa e/ou qualitativa. 


\section{MÉTODO}

Para a elaboração da revisão de literatura foi selecionada a bibliografia pertinente à temática de autores brasileiros e estrangeiros traduzidos e, depois da leitura, foi construído o texto com os autores relevantes e a discussão sobre as ideias apresentadas.

Com o detalhado e minucioso levantamento dos autores trabalhados nos estudos de qualidade ambiental urbana, principalmente, do núcleo sob orientação do Prof. Dr. João Carlos Nucci, foram sistematizados os critérios e os parâmetros utilizados para a avaliação da qualidade ambiental urbana, que são apresentados em forma de quadro ao final da discussão.

A construção da tabela tem a intenção de agrupar as informações trabalhadas nos estudos de qualidade ambiental urbana e, assim, facilitar os futuros estudos de avaliação da qualidade ambiental urbana.

\section{RESULTADOS E DISCUSSÃO}

\section{A Cidade e a Visão Ecológica}

Em 1972, Detwyler e Marcus constatavam que as questões ambientais urbanas tinham sido pouco estudadas e afirmavam a falta de estudos de Geografia Física que discutissem sobre a influência do homem na natureza, especialmente na cidade.

Cavalheiro $(2009)^{2}$ se apoia em Sukopp e Kunick (1973) para tratar sobre os estudos das cidades contemporâneas:

(...) a discussão sobre o ambiente do ser humano e seus riscos de sobrevivência concentram-se, principalmente, em considerações tecnológicas. A natureza e a paisagem como sistemas complexos raramente são incluídas nessas reflexões. Isso vale, principalmente, para as grandes cidades, o tipo de paisagem mais severamente ameaçado por poluição do ar, das águas e por resíduos sólidos. Embora elas sejam o ambiente mais importante do homem hodierno, são esparsas as tentativas de estudá-las, considerá-las e reconhecê-las como unidades funcionais (ecossistemas). (SUKOPP e KUNICK, 1973 apud CAVALHEIRO, 2009, p. 65-66).

\footnotetext{
${ }^{2}$ Artigo originalmente publicado no livro "Análise ambiental: uma visão multidisciplinar" (Sâmia TAUK et al. (orgs). Rio Claro/SP: UNESP/FAPESP, 1991).
} 
$\mathrm{Na}$ direção de realizar estudos sobre a qualidade do ambiente urbano, a Ecologia e a Geografia Física podem contribuir com conceitos e métodos (DOUGLAS, 1983). Estudos sobre o ambiente urbano são extremamente importantes, em primeiro lugar por ser o principal ambiente do homem contemporâneo e em segundo lugar por ser onde acontecem profundas alterações sobre a natureza devido ao intenso uso humano.

Sobre a cidade é importante considerar o volume e a intensidade das mudanças que têm ocorrido nos últimos tempos, sendo a industrialização, os transportes e a comunicação os fatores mais decisivos nestas mudanças, nas palavras de Monteiro (2008) a cidade é antes de tudo o testemunho do poder de veto do homem sobre a natureza.

Lombardo (1985) afirma que é no espaço urbano que os problemas ambientais atingem maior amplitude, assim, é possível observar maior concentração de poluentes do ar, água e degradação do solo e subsolo, em consequência do uso intenso do território pelas atividades urbanas.

Mesmo com tantas interferências do homem sobre a natureza, a cidade pode ser considerada como qualquer sistema natural, pois todas as suas partes são interligadas e interdependentes, consequentemente, uma mudança em uma parte da cidade resulta em mudanças em outras (DIAS, 2002).

Assim sendo, as condições geoecológicas da cidade são específicas, que alteram de forma profunda as condições naturais básicas com reflexos decisivos sobre a biosfera (TROPPMAIR, 2004). A Figura 1 evidencia as alterações profundas da biosfera urbana.

Dentre as alterações que acontecem na biosfera urbana, estão as variações climáticas. Lombardo (1985) afirma que a urbanização, considerada em termos de espaço físico construído, altera significativamente o clima urbano, dentre os aspectos modificados estão o aumento das superfícies de absorção térmica, a impermeabilização dos solos, as alterações na cobertura vegetal, a concentração de edifícios que interferem nos efeitos dos ventos, a contaminação da atmosfera através da emanação dos gases.

Um importante evento é a formação de ilhas de calor (AYOADE, 1983; LOMBARDO, 1985; DANNI-OLIVEIRA, 2003), fenômeno que acontece especialmente em grandes cidades e, de forma simplificada, explica-se pela 
diferença de temperatura entre a área urbana e a zona rural adjacente. As ilhas de calor estão associadas à redução das trocas de ar, a alterações da umidade do ar e da precipitação, que trazem como resultado a concentração de poluição no ar que não consegue se dissipar, dentre outros resultados negativos.

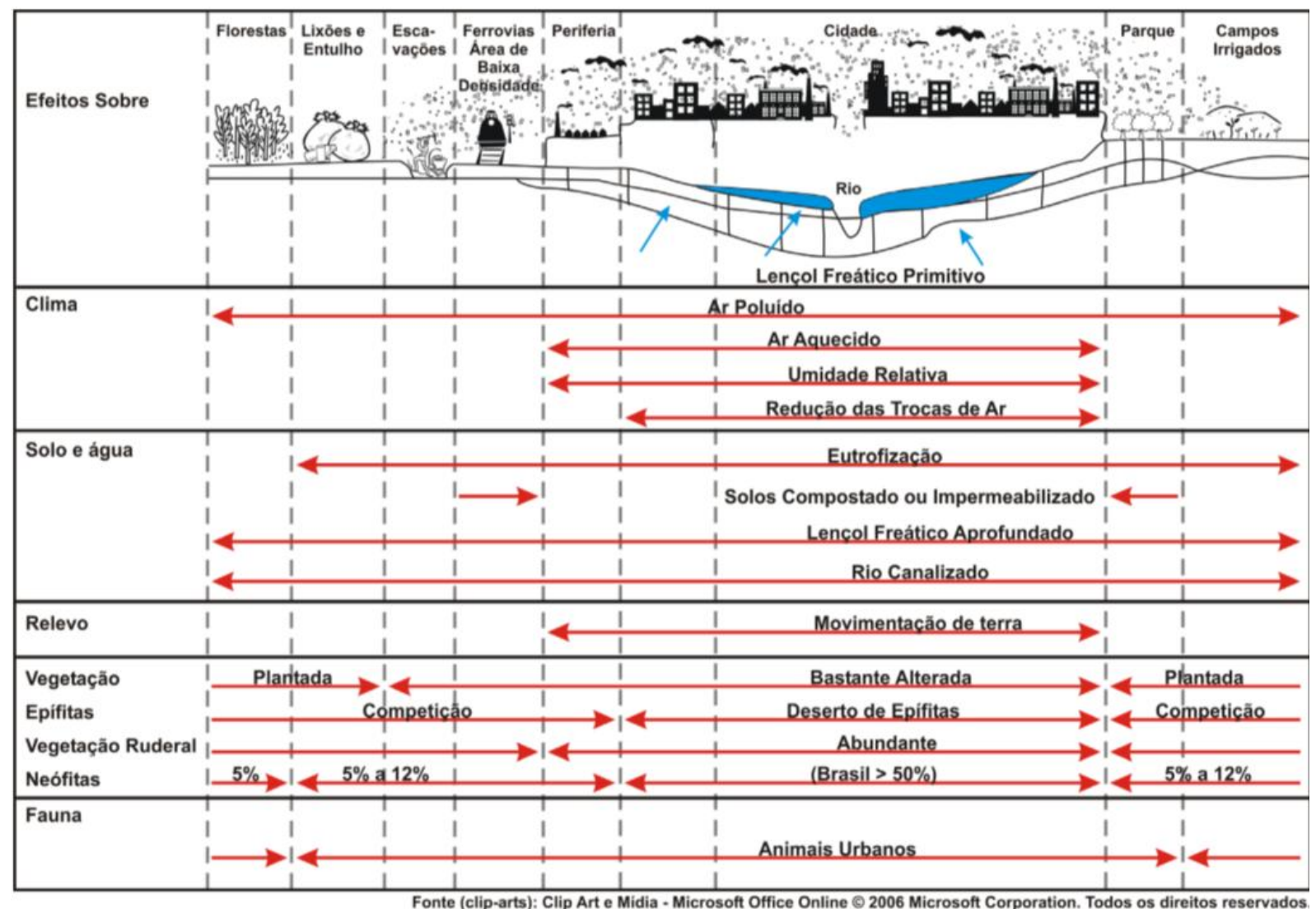

Figura 1: Principais alterações da biosfera em áreas urbanizadas.

Fonte: Sukopp e Kunick (1973), modificado por Cavalheiro (1991, 2009).

Organização: Michelle C. M. Silva (2006).

"Uma das consequências da ilha de calor na cidade é a formação de uma circulação do ar característica, onde o ar da região central se aquece e sobe, e o ar da periferia converge para o centro da cidade, onde se encontra o pico da ilha de calor, formando-se, assim, um domo de poluição sobre a cidade" ( $\mathrm{NUCCl,} \mathrm{2008,}$ p.13).

As ilhas de calor são decorrentes das ações antrópicas, caracterizadas pela ocorrência de edificações, que constituem rugosidades, e pelas alterações da natureza urbana. O calor é aumentado na cidade pela presença das construções (asfalto, telhados, edificações), que retêm a temperatura, variam o albedo e diminuem a circulação dos ventos; também pela presença de cobertura vegetal 


\section{A QUESTÃo ECOLÓGICA URBANA E A QUALIDADE AMBIENTAL URBANA}

insuficiente e pela predominância de áreas impermeáveis (LOMBARDO, 1985; $\mathrm{NUCCl}, 2008)$.

Outra alteração na biosfera da cidade é o aumento do escoamento superficial (runoff) da água da chuva, que, da mesma forma, é consequência da predominância da impermeabilização do solo e da ausência de cobertura vegetal suficiente, tendendo a elevar a ocorrência de inundações nas áreas baixas da cidade, como é o caso das várzeas.

Essas transformações da biosfera exemplificam a variação da qualidade ambiental que pode ser observada na cidade, quando analisados os componentes biofísicos, sua estrutura e dinâmica. Essa é a perspectiva ecológica, que trata de analisar as características físicas e biológicas que compõem a cidade, entendendo as inter-relações existentes entre seus elementos constituintes, que são diferentes do seu entorno rural. A perspectiva ecológica é empregada por diversos autores em seus trabalhos e alguns são descritos a seguir.

A obra de Detwyler e Marcus (1972), Urbanization and Environment, objetivou: (1) demonstrar como o homem tem modificado o ambiente natural com a urbanização; (2) sugerir como as feições físicas e processos influenciam o crescimento e o funcionamento das cidades; e (3) revisar algumas retroalimentações entre ações humanas e processos ambientais. Portanto, os autores trabalharam o ecossistema urbano com o objetivo de melhor entender o funcionamento da cidade.

Tricart (1977) discutiu sobre a susceptibilidade do solo a certos usos, salientando a necessidade de um diagnóstico preliminar das características do local, para posterior efetuação do zoneamento, assim, seriam identificadas as limitações da área em questão.

Gomes Orea (1978) trabalhou a dimensão física do planejamento como sendo a oferta para os possíveis usos. Com base no inventário e posterior mapeamento das características físicas, biológicas e culturais foi realizada a valoração dos temas em termos de suas qualidades ou graus de excelência, relacionando-os aos usos, para, então, chegar à prognose, estabelecendo a relação uso e território, podendo prever o comportamento do território supondo que sobre ele se estabeleça um uso.

Monteiro $(1987,2000)$ desenvolveu o estudo "Qualidade Ambiental na Bahia - Recôncavo e Regiões Limítrofes”, com início em 1983, assentada sob a 
concepção geossistêmica (de paisagem), com o objetivo de elaborar propostas para atingir uma maior a qualidade ambiental.

\begin{abstract}
O tratamento geossistêmico visa a integração das variáveis "naturais" e "antrópicas" (Etapa Análise), fundindo "recursos", "usos" e "problemas" configurados (Etapa Integração) em "unidades homogêneas" assumindo um papel primordial na estrutura espacial (Etapa Aplicação) do "Diagnóstico". (MONTEIRO, 2000, p.81).
\end{abstract}

No planejamento, McHarg (2000) propôs incorporar ao mapeamento dos fatores ambientais, os fatores do meio físico e, depois, fazer uma análise comparativa observando a susceptibilidade dos vários usos da terra, determinando cores e tons para tal. Esse método indica áreas com maior capacidade de suporte e autorregulação, assim como áreas de maior vulnerabilidade ambiental.

Os estudos citados apontam que a cidade deve ser observada por seus aspectos biofísicos. Sukopp (1998) lembra que embora a maioria dos fatores que afetam os ecossistemas urbanos também atue em áreas não urbanas, a combinação desses fatores leva à conclusão de que ecossistemas únicos se desenvolvem com combinações de espécies peculiares às áreas urbanas. E, por esse motivo, devem ser investigados.

Em consequência da interferência humana, as cidades ou sistemas ecológicos únicos adquirem as seguintes características ecológicas (SUKOPP E WERNER, 1991):

- A produção e o consumo de energia secundária são altos;

- Grande importação e exportação de materiais, enorme quantidade de dejetos. Elevação em vários metros da superfície do solo (verticalização);

- Forte contaminação do ar, do solo e da água;

- Diminuição das águas subterrâneas;

- Destruição do solo;

- Desenvolvimento de um clima tipicamente urbano, com maiores temperaturas e baixa umidade relativa (ilha de calor);

- Desequilíbrio em favor dos organismos consumidores, baixa produtividade primária e débil atividade dos organismos detritívoros.

- Mudanças fundamentais nas populações vegetais e animais. 
Diante do exposto, observa-se o entendimento desses autores de que a cidade é vista funcionalmente como um ecossistema ${ }^{3}$. E, apresenta as seguintes características: exerce grande pressão sobre os sistemas naturais, depende deles para a entrada de recursos (matéria e energia) e, também, para a eliminação dos resíduos (Figura 2).

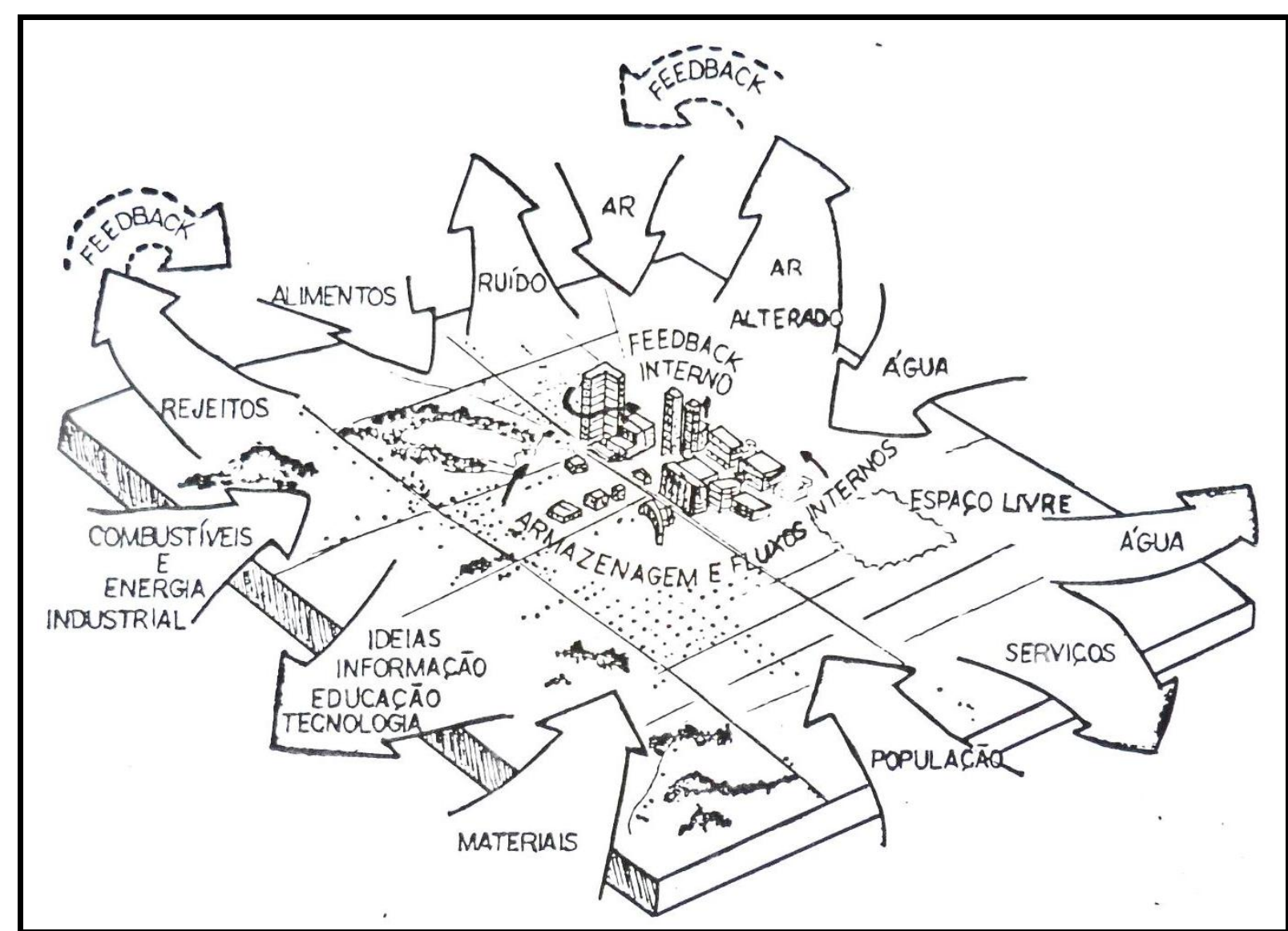

Figura 2: Representação esquemática de alguns inputs e outputs presentes nos ecossistemas urbanos.

Fonte: Detwyler e Marcus (1972).

Pensando o funcionamento da cidade sob a perspectiva ecossistêmica, há entradas (inputs) e saídas (outputs) de energia e matéria ${ }^{4}$. Enfim, a cidade sofre alterações em sua biosfera devido as transformações de seus componentes

\footnotetext{
${ }^{3}$ Troppmair (2004, p. 109) não considera as cidades como ecossistemas, mas como sistemas urbanos. Isso porque a cidade tem as características de entrada, retroalimentação e saídas de energia e matéria, porém, não se verifica a autorregulação e o equilíbrio.

${ }^{4}$ As cidades são altamente dependentes para a produção de energia e matéria, de outras áreas, vizinhas ou mesmo mais distantes. Ações e medidas ecológicas que visam diminuir esta dependência têm como objetivo que o meio urbano se torne, sucessivamente, um ecossistema mais autossuficiente.
} 
biofísicos ocasionados por ações do ser humano. Os resultados são as variações na qualidade ambiental urbana.

\section{Estudos de Avaliação da Qualidade Ambiental Urbana}

Com base em McHarg (1971), Monteiro (1987) e Kiemstedt e Gustedt (1990), Nucci (1996) desenvolveu um método para avaliar a qualidade ambiental na cidade, utilizando-se de indicadores baseados nos princípios do Planejamento da Paisagem. Nesse trabalho, Nucci levou em conta os seguintes critérios: uso do solo, poluição, verticalidade das edificações, densidade demográfica, enchentes, cobertura vegetal e espaços livres. Os critérios utilizados estão inter-relacionados e têm influência direta ou indireta uns sobre os outros.

O método de qualidade ambiental desenvolvido por Nucci (1996, 2001, 2008), inclusive sua base conceitual, foi detalhadamente descrita por Tonetti (2011, p. 35 e 36), e com pequenas alterações segue abaixo:

- a qualidade do ambiente atende à condição biológica do ser humano, que para suprir suas necessidades básicas, precisa de água, ar, alimento, espaço para interagir e energia, entre outras condições do ambiente;

- os aspectos culturais, sociais e econômicos não são abordados nessa delimitação de conceito;

- a qualidade implica na existência de uma amplitude de condições dos fatores ambientais para suprir as necessidades do ser humano biológico, que podem ser valores ou variações qualitativas com mínimos e máximos;

- o ambiente é constituído pelos aspectos físicos, químicos e biológicos do local estudado;

- questões ambientais, sociais, econômicas, culturais e existenciais não podem ser analisadas cientificamente em conjunto, pelo menos no momento atual do desenvolvimento científico, devido a falta de uma base teórica científica que abranja todas essas questões ao mesmo tempo. O que geralmente ocorre são estudos científicos individualizados para cada um desses aspectos, que poderão ser utilizados para uma síntese final, no âmbito da política, e não da ciência;

- o estudo da qualidade ambiental é feito pelo lado da "oferta", ou seja, o que o ambiente tem para oferecer para o ser humano e não o que o homem quer ou faz no 
ambiente em que vive e/ou trabalha. Dessa maneira, buscam-se os limites e aptidões do ambiente para suprir as necessidades biológicas do ser humano;

- os estudos de qualidade ambiental urbana buscam informações na literatura que indiquem quais seriam esses limites físicos, químicos e biológicos do ambiente que estariam dentro das condições adequadas à condição biológica do ser humano, ou seja, buscam-se parâmetros dentro de critérios selecionados para a avaliação do ambiente de vida do ser humano;

- essas informações, dentre outras formas, são inferidas principalmente com base nos dados do uso e ocupação do solo, conforme orientações da Ecologia da Paisagem em áreas urbanizadas, ou Ecologia Urbana (BREUSTE, 2002), juntamente com a literatura que fornece o suporte para serem inferidas informações sobre a poluição (visual, sonora, do ar, da água, do solo), a quantidade mínima de cobertura vegetal, a densidade demográfica e o limite das edificações, entre outros critérios utilizados para a construção da carta da qualidade ambiental do local estudado, portanto, as informações devem, preferencialmente, ser passíveis de mapeamento;

- a composição das condições desfavoráveis ou dos parâmetros negativos dos critérios ambientais, caracteriza menor qualidade ambiental. Da ausência das condições desfavoráveis até a sobreposição do maior número de parâmetros negativos, tem-se uma perda potencial da qualidade ambiental;

- a ausência de parâmetros negativos não significa que o local analisado apresente boa qualidade ambiental, mas que ele não apresenta nenhuma das condições desfavoráveis estudadas, podendo apresentar outras condições que não foram analisadas na pesquisa realizada.

Em resumo e de forma bastante simplificada, as características do método de qualidade ambiental são: utilização da visão sistêmica; definição de critérios pertinentes, óbvios e simples ${ }^{5}$, para a avaliação da qualidade ambiental com base nos princípios da Ecologia e do Planejamento da Paisagem; identificação de parâmetros que sirvam como indicação para a população e os gestores urbanos, no sentido de instrumentalizá-los para discutir as questões relacionadas às informações

\footnotetext{
${ }^{5}$ Os critérios devem ser óbvios e simples para permitir que a população realize inferências sobre como esses critérios interferem na qualidade ambiental urbana.
} 
locais; inferências que definem a qualidade ambiental urbana por intermédio de tais critérios e parâmetros; mapeamento das informações.

Tonetti (2011) salienta que a primeira edição do livro "Qualidade Ambiental e Adensamento Urbano" (2001) é um marco no Brasil para o desenvolvimento dos trabalhos sobre qualidade ambiental urbana com base na Ecologia e no Planejamento da Paisagem. Esse livro é o resultado da tese de doutorado do Prof. João Carlos Nucci junto ao Departamento de Geografia na Universidade de São Paulo em 1996, sob a orientação do Prof. Dr. Felisberto Cavalheiro.

Desde então, houve diversas contribuições para os estudos de avaliação da qualidade ambiental urbana. Como Valaski (2013), que trouxe contribuições para o método desenvolvido por Nucci (1996) ao elaborar uma chave de classificação e interpretação (legendas) das paisagens para o mapeamento urbano. As legendas trazem inferências sobre a estrutura e a dinâmica das paisagens, facilitando o entendimento do ecossistema urbano e contribuindo para a visão sistêmica da cidade.

Com cerca de vinte anos de história, no Brasil os estudos de qualidade ambiental urbana tem quatro grupos de pesquisa que merecem destaque:

- Sob a orientação do Prof. Dr. João Carlos Nucci na Universidade Federal do Paraná em Curitiba/PR ;

- Sob a orientação da Prof ${ }^{a}$. Dr ${ }^{a}$. Margarete Cristina da Costa Trindade Amorim na Universidade Estadual Paulista Júlio de Mesquita Filho em Presidente Prudente/SP;

- Sob a orientação da Prof ${ }^{a}$. Dr ${ }^{a}$. Oriana Aparecida Fávero na Universidade Presbiteriana Mackenzie em São Paulo/SP;

- Sob a orientação do Prof. Dr. Yuri Tavares Rocha na Universidade de São Paulo em São Paulo/SP.

Devido ao volume e a regularidade na produção de trabalhos científicos ${ }^{6}$ sobre a qualidade ambiental urbana, Tonetti (2011, p. 42) considerou a constituição de uma escola de estudos da qualidade ambiental urbana no Brasil, fundamentada nos princípios da Ecologia e do Planejamento da Paisagem e que objetivam auxiliar e propor medidas para a gestão e o planejamento do ambiente urbano.

\footnotetext{
${ }^{6}$ Sobre a quantificação e relação temporal, até janeiro de 2010 , da produção científica sobre qualidade ambiental urbana nos quatro grupos de pesquisa destacados consultar Tonetti (2011, p. 43).
} 
Há diversos trabalhos que discutem e se aprofundam nos critérios para a avaliação da qualidade ambiental urbana. De maneira geral, os critérios são os seguintes:

$>\quad$ Verticalidade das edificações;

$>$ Densidade demográfica;

$>$ Enchentes;

$>$ Cobertura vegetal;

$>$ Espaços livres;

$>$ Poluição do ar;

$>$ Poluição sonora;

$>$ Usos potencialmente poluidores.

Com relação aos parâmetros dos critérios de qualidade ambiental urbana há uma fundamental bibliografia. Mas existem também os parâmetros definidos por outras fontes, como pela legislação, por exemplo. A legislação brasileira define alguns parâmetros por intermédio de resoluções e de normas técnicas.

Esse é o caso da poluição sonora, em que a NBR 10151 (ABNT, 2000) delimita os parâmetros para avaliação desse critério em diferentes tipos de área (Tabela 1).

Tabela 1: Nível de critério de avaliação (NCA) para ambientes externos, em dB(A) ${ }^{7}$

\begin{tabular}{|l|c|c|}
\hline \multicolumn{1}{|c|}{ Tipos de áreas } & Diurno & Noturno \\
\hline Áreas de sítios e fazendas & 40 & 35 \\
\hline Área estritamente residencial urbana ou de hospitais ou de escolas & 50 & 45 \\
\hline Área mista, predominantemente residencial & 55 & 50 \\
\hline Área mista, com vocação comercial e administrativa & 60 & 55 \\
\hline Área mista, com vocação recreacional & 65 & 55 \\
\hline Área predominantemente industrial & 70 & 60 \\
\hline
\end{tabular}

Fonte: ABNT, NBR 10151, 2000.

O Quadro 1 levanta duas questões relevantes. Em primeiro lugar, há uma divisão de áreas, enquanto, se observa na cidade uma mistura de usos, o que dificulta a análise precisa desses parâmetros. Na cidade o uso residencial está

\footnotetext{
7 "Nível de pressão sonora equivalente $\left(L_{\text {Aeq }}\right)$, em decibéis ponderados em " $A$ " [dB $\left.(A)\right]$ : Nível obtido a partir do valor médio quadrático da pressão sonora (com a ponderação $A$ ) referente a todo o intervalo de medição" (ABNT, NBR 10151, 2000).
} 
associado ao uso comercial e de serviços, a hospitais, a escolas, a pequenas indústrias, quando não indústrias de grande porte.

Ao definir uma área como predominantemente industrial significa dizer que o uso mais expressivo é o da indústria. A palavra "predominantemente" dá a ideia de que a maioria dos usos é o industrial, mas que podem ocorrer outros usos associados, como possivelmente o residencial. Diante do exposto, é possível concluir que a população residente deverá se adaptar ao nível de ruídos pois a área é definida com o predomínio da atividade industrial. É difícil definir parâmetros e delimitar áreas quando a cidade é constituída por usos incompatíveis e inconvenientes.

A segunda questão diz respeito aos parâmetros estabelecidos pela norma, pois ao defini-los não traz uma discussão pertinente sobre a saúde da população e do ambiente. A Organização Mundial da Saúde (OMS) classifica como nocivos os ruídos constantes acima de $55 \mathrm{~dB}$ durante o dia, e durante a noite os ruídos acima de $40 \mathrm{~dB}^{8}$.

A poluição sonora foi um exemplo de um critério com parâmetros já consagrados pela legislação, mas existem outros como a qualidade da água e a qualidade do ar. Nesses critérios, a avaliação é realizada por instrumentos e são definidos padrões de qualidade ou parâmetros que permitem identificar o índice de qualidade dos diferentes elementos analisados.

Nos estudos de qualidade ambiental urbana, os parâmetros servem de informação, como ponto de partida, para a discussão dos indicadores; e assim sendo, conclui-se que não podem ser números rígidos, pois as paisagens são diferentes, assim como a cultura das pessoas de cada local.

Outro ponto pertinente é que os parâmetros precisam ser reconhecidos sem a necessidade de instrumentos, que acabam restringindo a identificação dos números aos poucos que detêm tais instrumentos e, essa tecnologia, pode dificultar o entendimento da população envolvida, devido à utilização de conceitos puramente técnicos, como exemplificado pela unidade de medida para a poluição sonora.

Por outro lado, como defende Tonetti (2011, p. 56), "as pesquisas sobre os níveis de poluição podem servir de alerta para a comunidade e para o poder público,

\footnotetext{
8 Informação disponível em http://www.cabesp.com.br/home/Materia/Visualizar/340 (acesso em 01/07/2015).
} 
de que novos hábitos de vida e novas políticas públicas devam ser adotadas para melhoria da qualidade do ambiente urbano".

De maneira geral, os critérios utilizados nos estudos de qualidade ambiental urbana estão inter-relacionados e, portanto, causam interferência uns sobre os outros. Quando o uso do solo é transformado, todos os demais indicadores de qualidade ambiental urbana sofrem alterações, que podem variar: mudanças na impermeabilização do solo, na taxa de escoamento superficial, na verticalidade, na densidade demográfica, na cobertura vegetal e nos espaços livres.

A Tabela 2 traz os índices de espaços urbanos em algumas cidades da Alemanha. Para a organização da Tabela, os tipos de espaços que compõem o solo urbano foram divididos em: espaços livres de edificações e espaços com edificações, ao qual se somou o sistema viário.

Tabela 2: Índices de espaços urbanos em diferentes cidades da Alemanha.

\begin{tabular}{|c|c|c|c|c|c|c|}
\hline $\begin{array}{c}\text { Tipos de } \\
\text { espaços }\end{array}$ & $\begin{array}{c}\text { Berlim } \\
(\%)\end{array}$ & $\begin{array}{c}\text { Hamburgo } \\
(\%)\end{array}$ & $\begin{array}{c}\text { Munique } \\
(\%)\end{array}$ & $\begin{array}{c}\text { Colônia } \\
(\%)\end{array}$ & $\begin{array}{c}\text { Frankfurt } \\
(\%)\end{array}$ & $\begin{array}{c}\text { Hannover } \\
(\%)\end{array}$ \\
\hline $\begin{array}{c}\text { Espaços } \\
\text { livres de } \\
\text { edificações }\end{array}$ & 45 & 54 & 43 & 53 & 60 & 53 \\
\hline $\begin{array}{c}\text { Espaços } \\
\text { com } \\
\text { Edificações } \\
+ \text { Sistema } \\
\text { Viário }\end{array}$ & 55 & 46 & 57 & 47 & 40 & 47 \\
\hline
\end{tabular}

Fonte: Berlim (2001 apud PIVETTA et al., 2005).

Organização: Estêvez (2014).

O menor índice de espaços livres de edificações é encontrado em Munique com $43 \%$, contra $57 \%$ de espaços com edificações e sistema viário. Enquanto, Frankfurt apresentou $60 \%$ de espaços livres de edificações, o maior valor para esse índice entre as cidades, e $40 \%$ de espaços com edificações e sistema viário.

Esses valores, que giram em torno de $50 \%$ entre espaços com edificações e os livres de edificações, reforçam a importância dos espaços livres nas áreas urbanas. Essa relevância, para as funções ecológicas da natureza na cidade, aumenta caso os espaços livres apresentem cobertura vegetal.

Inversamente, caso os espaços com edificações apresentem verticalidade, ocorre o aumento da densidade demográfica e os espaços livres de edificação sofrem pressões, e mais, a cobertura vegetal tende a não ser suficiente. A 
consequência dessa situação é o aumento da poluição do ar, da poluição sonora, dos pontos de enchentes e das alterações microclimáticas.

Como apresentado anteriormente, os critérios já foram extensamente discutidos e são intrínsecos aos estudos de avaliação da qualidade ambiental urbana. Assim, considerou-se não haver a necessidade de trazer para o artigo essa revisão pormenorizada. Para tanto, foi realizado o levantamento das informações sobre os critérios e os parâmetros utilizados nos estudos de qualidade ambiental urbana, com base nos princípios da Ecologia e do Planejamento da Paisagem, com o objetivo de sistematizar tais informações. O resultado é apresentado na Tabela 3.

Para alguns critérios, como cobertura vegetal, espaços livres e poluição sonora, foram encontrados variados parâmetros. Enquanto, para os indicadores como usos potencialmente poluidores e enchentes ainda não há valores numéricos que sirvam de base para a análise da qualidade ambiental urbana. Com relação à densidade demográfica, é interessante observar as discrepâncias entre os parâmetros apresentados.

Os diferentes parâmetros para um mesmo critério corroboram o aviso de que os parâmetros não são o resultado em si, mas que servem como base de informação para a avaliação da qualidade ambiental urbana, pois esta avaliação depende das características biofísicas do local e da cultura da sociedade em que esta paisagem está inserida.

Valaski (2008) ressalta que o ordenamento dos usos humanos na paisagem deve reconhecer e respeitar os limites do ambiente para explorar da melhor maneira possível suas aptidões, configurando-se como um caminho a ser seguido para um desenvolvimento que tenha como propósito minimizar os impactos negativos no ambiente urbano.

McHarg (2000, p. 127) reitera a importância de se ter em mente que é necessário compreender a natureza como um processo interativo que representa um sistema de valores relativos e que se pode interpretar como uma oferta de oportunidades de uso, mas também levanta restrições, inclusive proibições, para alguns usos. 
Tabela 3: Critérios e parâmetros utilizados nos estudos de qualidade ambiental urbana.



(Continua) 


\begin{tabular}{|c|c|c|c|}
\hline $\begin{array}{l}\text { COBERTURA } \\
\text { VEGETAL }\end{array}$ & $\begin{array}{c}\text { Em estudo em Hong Kong apresentou } \\
\text { uma classificação dos diferentes tipos de } \\
\text { manchas de cobertura vegetal arbórea } \\
\text { com base na distribuição espacial e na } \\
\text { forma: } \\
\text { - isolated (dispersed, clustered, clumped) } \\
\text { - linear (rectilinear, curvilinear, annular) } \\
\text { - connected (reticulate, ramified, } \\
\text { continuous) } \\
\text { Sobre o estudo de Jim (1989), apesar da } \\
\text { sua importância, poderia considerar o } \\
\text { porte da vegetação, pois "a quantidade e } \\
\text { a distribuição de suas categorias, ou } \\
\text { seja, herbácea, arbustiva ou arbórea, } \\
\text { estão relacionadas com conforto térmico, } \\
\text { com a qualidade do ar, escoamento } \\
\text { superficial, uso pela população, etc." } \\
\text { Do ponto de vista climático em uma } \\
\text { cidade, uma distribuição mais uniforme } \\
\text { de pequenos espaços arborizados é mais } \\
\text { efetiva que a concentração de poucos } \\
\text { lugares grandes. Este autor ainda } \\
\text { comenta que as copas das árvores de } \\
\text { uma rua podem absorver grandes } \\
\text { quantidades de energia e reduzir a } \\
\text { temperatura em até } 6{ }^{\circ} \mathrm{C} \text { em relação a } \\
\text { ruas não sombreadas }\end{array}$ & $\begin{array}{l}\text { Jim (1989 apud } \\
\text { NUCCI e } \\
\text { CAVALHEIRO, } \\
\text { 1999) }\end{array}$ & $\begin{array}{l}\text { Com base na Ecologia } \\
\text { da Paisagem, quanto } \\
\text { mais conectada é a } \\
\text { cobertura vegetal, } \\
\text { melhor para a } \\
\text { qualidade ambiental }\end{array}$ \\
\hline \multirow[t]{2}{*}{$\begin{array}{l}\text { ESPAÇOS } \\
\text { LIVRES }\end{array}$} & $\begin{array}{l}\text { Propõe índices de espaços livres com } \\
\text { base em estudos de conjuntos } \\
\text { habitacionais e no número de } \\
\text { residências. Para avaliar a demanda } \\
\text { devem-se considerar as características } \\
\text { demográficas, econômicas e sociais da } \\
\text { população. Um conjunto residencial, } \\
\text { segundo o autor em questão, pode ter } \\
\text { seus espaços divididos em: } \\
\text { - área construída ( } 37,8 \%) \\
\text { - sistema viário e estacionamentos } \\
\text { (19,6\%) } \\
\text { - sistema de espaços livres (42,6\%) com } \\
17,32 \mathrm{~m}^{2} / \mathrm{hab}^{2} \\
\text { máximo } 500 \text { mil habitantes: o sistema de } \\
\text { espaços livres teria } 50,0 \mathrm{~m}^{2} / \text { hab, sendo } \\
35 \mathrm{~m}^{2} / \text { hab totalmente públicos e livres de } \\
\text { regras rígidas }\end{array}$ & Llardent (1982) & \multirow[t]{2}{*}{$\begin{array}{l}\text { Caracterizados por } \\
\text { áreas não edificadas } \\
\text { Para Sukopp e Wener } \\
\text { (1991) a densidade de } \\
\text { edificações determina } \\
\text { as possibilidades de } \\
\text { reverdecimento do } \\
\text { centro urbano. A } \\
\text { densidade de } \\
\text { edificação deverá } \\
\text { também planificar- se } \\
\text { de tal maneira que se } \\
\text { consiga uma densidade } \\
\text { média em vez de uma } \\
\text { densidade máxima (por } \\
\text { exemplo, que se possa } \\
\text { edificar ou pavimentar } \\
\text { no máximo dois terços } \\
\text { da superfície do } \\
\text { centro)" }\end{array}$} \\
\hline & $\begin{array}{l}\text { Na Carta de Londrina e lbiporã, encontra- } \\
\text { se como proposta de índice mínimo de } \\
\text { áreas verdes públicas destinadas à } \\
\text { recreação o valor de } 15 \mathrm{~m}^{2} / \mathrm{hab} \text {. }\end{array}$ & $\begin{array}{l}\text { Sociedade } \\
\text { Brasileira de } \\
\text { Arborização } \\
\text { Urbana (março } \\
\text { de 1996) }\end{array}$ & \\
\hline
\end{tabular}

(Continua) 


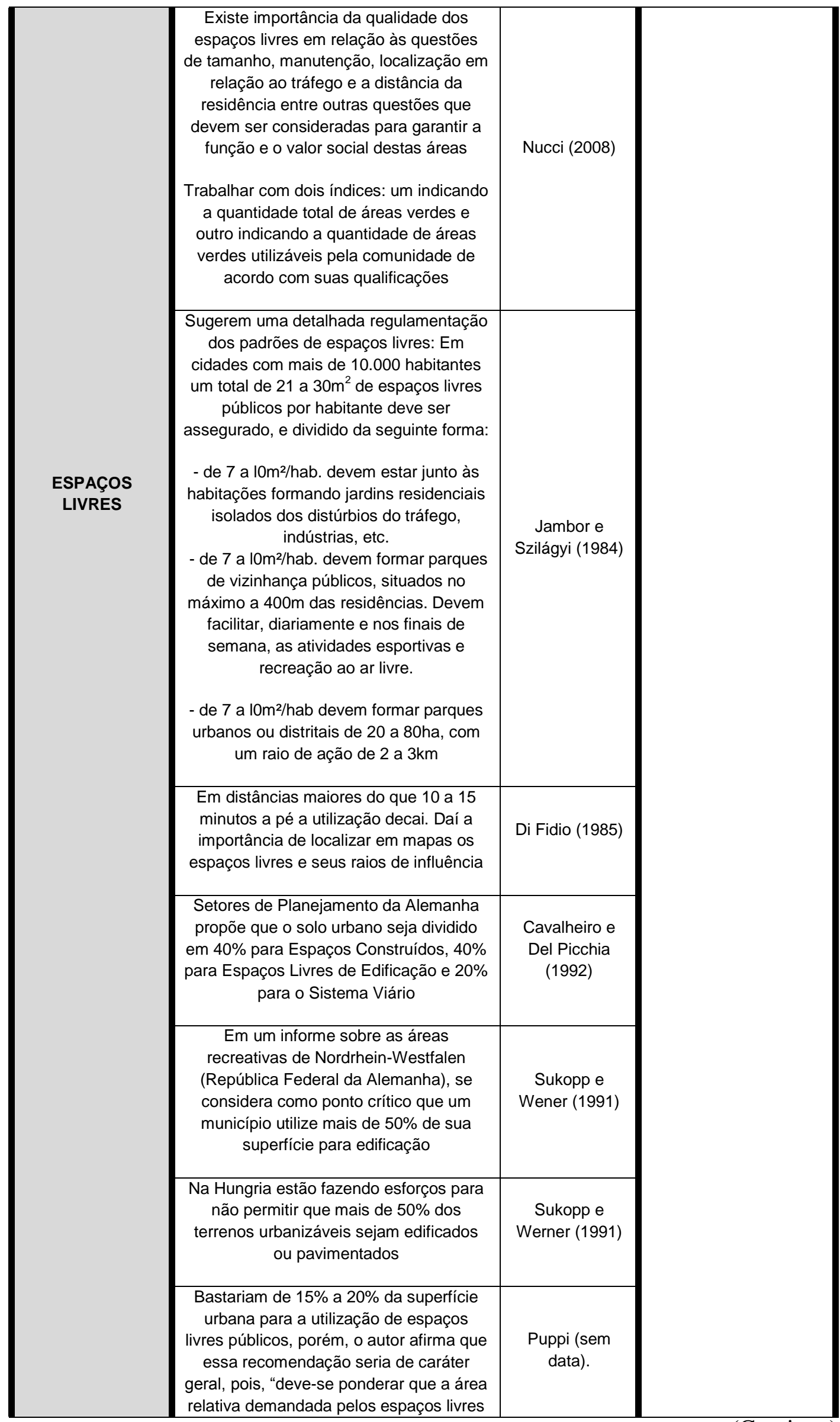
espaços livres em relação às questões e tamanho, manutenção, localização em relação ao tráfego e a distância da vem ser consideradas para garantir a

rabalhar com dois índices: um indicando a quantidade total de áreas verdes $e$ outro indicando a quantidade de áreas rdes utilizáveis pela comunidade de

Sugerem uma detalhada regulamentação dos padrões de espaços livres: Em com mais de 10.000 habitantes total de 21 a $30 \mathrm{~m}^{2}$ de espaços livres pulicos por habitante deve ser

- de $7 \mathrm{a} 10 \mathrm{~m}^{2} / \mathrm{hab}$. devem estar junto às abitações formando jardins residenciais indústrias, etc.

de 7 a $10 \mathrm{~m}^{2} / \mathrm{hab}$. devem formar parques vizinhança públicos, situados no facilitar, diariamente e nos finais de recreação ao ar livre.

- de 7 a $10 \mathrm{~m}^{2} /$ hab devem formar parques anos ou distritais de 20 a $80 \mathrm{ha}$, com

Em distâncias maiores do que 10 a 15 minutos a pé a utilização decai. Daí a importância de localizar em mapas os

de Planejamento da Alemanha m $40 \%$ para Espaços Construídos, $40 \%$ para Espaços Livres de Edificação e 20\% (1992)

Em um informe sobre as áreas recreativas de Nordrhein-Westfalen (República Federal da Alemanha), se considera como ponto crítico que um município utilize mais de $50 \%$ de sua 


\begin{tabular}{|c|c|c|}
\hline $\begin{array}{l}\text { ESPAÇOS } \\
\text { LIVRES }\end{array}$ & $\begin{array}{c}\text { cresce com a densidade demográfica e } \\
\text { com a população" }\end{array}$ & $\begin{array}{c}\text { Sukkop e } \\
\text { Werner (1991) }\end{array}$ \\
\hline \multirow[t]{3}{*}{$\begin{array}{c}\text { POLUIÇÃO DO } \\
\text { AR }\end{array}$} & $\begin{array}{c}\text { Monóxido de Carbono: aqueles que } \\
\text { trabalham próximos a ruas } \\
\text { movimentadas das grandes cidades são } \\
\text { os mais afetados } \\
\text { Cita exemplos de poluentes que se } \\
\text { dispersam de vias arteriais até a } \\
\text { distância de 50m para ambos os lados a } \\
\text { partir dos limites da via. Escolas, casas e } \\
\text { áreas de lazer devem ser construídas a } \\
\text { mais de } 45 \mathrm{~m} \text { de distância da rua e } \\
\text { preferencialmente separadas por um } \\
\text { cinturão de árvores suficientemente } \\
\text { espaçadas para permitir a circulação do } \\
\text { ar sob suas copas. E, as hortas } \\
\text { comunitárias devem ficar a mais de } 15 \mathrm{~m} \\
\text { das ruas com tráfego intenso }\end{array}$ & $\begin{array}{l}\text { Fellemberg } \\
\text { (1980) }\end{array}$ \\
\hline & $\begin{array}{l}\text { O melhor bioindicador da qualidade do ar } \\
\text { pode ser o próprio ser humano, visto que } \\
\text { o número de internações, e mortes } \\
\text { relacionadas, aumenta com a redução da } \\
\text { qualidade do ar }\end{array}$ & Nucci (2008) \\
\hline & $\begin{array}{l}\text { Nos centros urbanos os problemas } \\
\text { respiratórios, como a asma, estão } \\
\text { relacionados ao aumento dos níveis de } \\
\text { poluentes emitidos pelos automóveis }\end{array}$ & Jackson (2003) \\
\hline \multirow[t]{2}{*}{$\begin{array}{l}\text { POLUIÇÃO } \\
\text { SONORA }\end{array}$} & $\begin{array}{l}\text { Os ruídos entre } 50 \text { a } 60 \text { decibéis podem } \\
\text { causar leve incômodo em pessoas mais } \\
\text { sensíveis; } 61 \text { a } 70 \text { decibéis podem } \\
\text { causar desconforto, irritabilidade, } \\
\text { mudança no humor e dificuldade de } \\
\text { concentração; } 71 \text { a } 80 \text { decibéis aumento } \\
\text { da pressão arterial e do batimento } \\
\text { cardíaco, fadiga e disfunções } \\
\text { gastrointestinais; } 81 \text { a } 90 \text { decibéis perda } \\
\text { auditiva e dor de cabeça; e, acima de } 100 \\
\text { decibéis pode causar dor e perda auditiva }\end{array}$ & $\begin{array}{l}\text { Folha de São } \\
\text { Paulo } \\
\text { (02/05/2002 } \\
\text { apud ZORZAL } \\
\text { et al., 2003) }\end{array}$ \\
\hline & $\begin{array}{l}\text { O nível de ruído de } 55 \text { decibéis pode } \\
\text { causar distúrbios no sono; } 70 \text { decibéis } \\
\text { seria o limite do considerado seguro, } \\
\text { podendo comprometer a aprendizagem; } \\
75 \text { decibéis, irritação e desconforto; } 80 \\
\text { decibéis, aumento dos batimentos } \\
\text { cardíacos, descarga de adrenalina no } \\
\text { organismo e hipertensão; } 90 \text { decibéis, } \\
\text { danos ao sistema auditivo; } 110 \text { decibéis, } \\
\text { danos permanentes à audição; e, } 140 \\
\text { decibéis limite máximo da audição }\end{array}$ & $\begin{array}{l}\text { Organização } \\
\text { Mundial de } \\
\text { Saúde }(1980, \\
\text { apud } \\
\text { BUCCHERI } \\
\text { FILHO e } \\
\text { TONETTI, } \\
\text { 2010) }\end{array}$ \\
\hline
\end{tabular}

(Continua) 


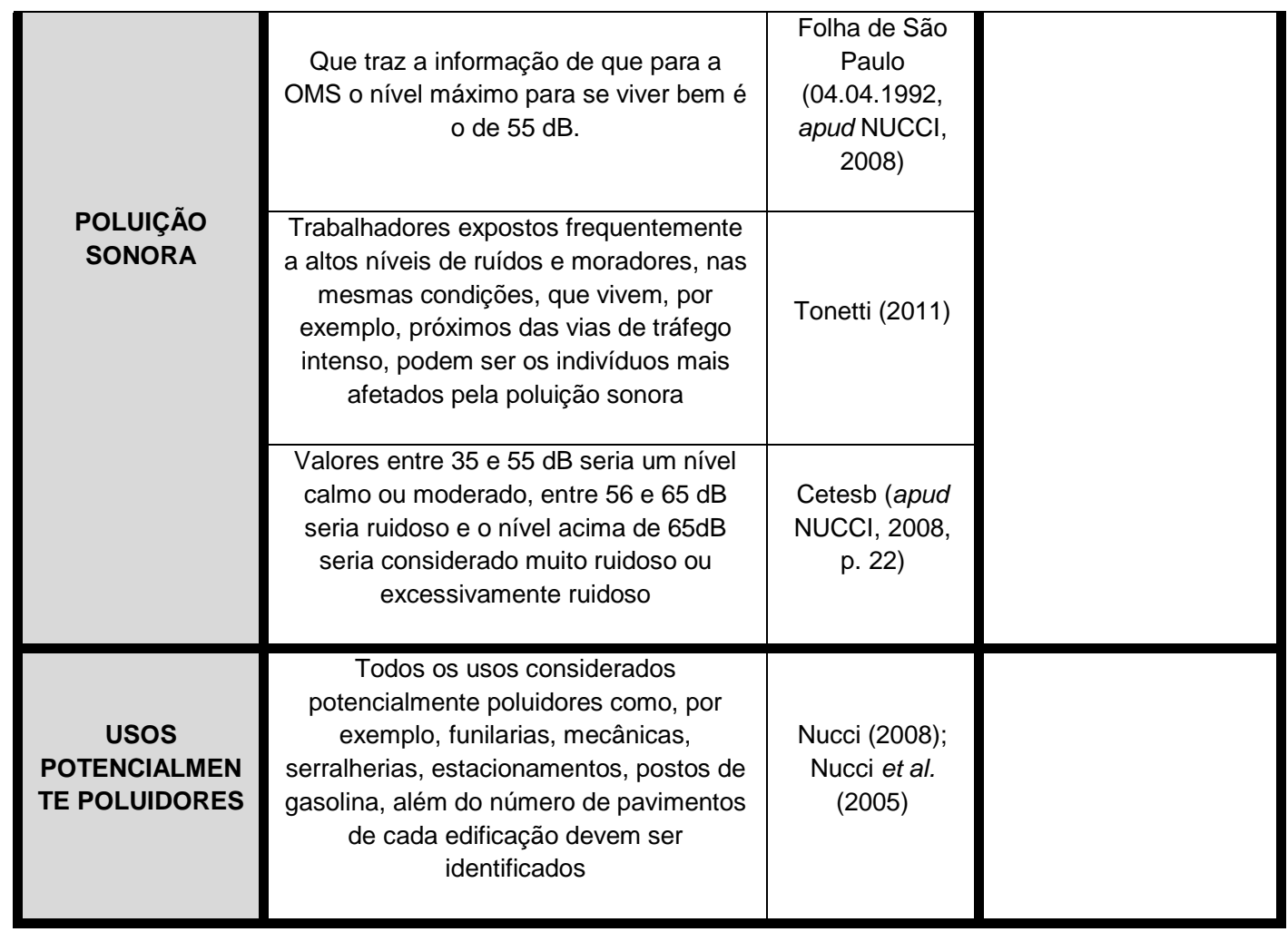

Fonte: Trabalhos de qualidade ambiental do grupo de pesquisa de Curitiba-PR. Elaboração: Estêvez (2014).

\section{CONSIDERAÇÕES FINAIS}

Os estudos de qualidade ambiental urbana dão aporte para entender as alterações na biosfera da cidade. Alterações sucessivas que se devem ao acelerado e contínuo processo de crescimento das cidades, tanto em extensão como em volume. Esse crescimento das cidades tem provocado os impactos sobre 0 ambiente urbano.

Se as potencialidades (limites e aptidões) do ambiente urbano fossem conhecidas e respeitadas na elaboração e execução do planejamento municipal, certamente, haveria melhora na qualidade ambiental urbana, pois os impactos negativos seriam reduzidos ou evitados.

Nesse sentido, os estudos de avaliação da qualidade ambiental urbana têm muito a oferecer, desde a ponderação da atual situação do ambiente urbano, passando por estudos de avaliação de impactos ambientais, até o planejamento urbano. 


\section{Referências}

ASSOCIAÇÃO BRASILEIRA DE NORMAS TÉCNICAS. NRB 10151: parâmetros para os níveis de ruídos. Rio de Janeiro, 2000. Disponível em http://www.semace.ce.gov.br/wp-

content/uploads/2012/01/Avalia\%C3\%A7\%C3\%A3o+do+Ru\%C3\%ADdo+em+\%C3 $\% 81$ reas+Habitadas.pdf. Acesso em 04/07/2013.

AYOADE, J. Introdução à climatologia para os trópicos. São Paulo: DIFEL, 1983. $332 p$.

BOLUND, P. e HUNHAMMAR, S. Ecosystem services in urban areas. Ecological Economics, 29 (1999) p. 293-301.

BRAGA, R. Aspectos da ordenação territorial nas leis orgânicas municipais do Estado de São Paulo. DG-FFLCH-USP, dissertação de mestrado, 1993.

BREUSTE, J. URBAN ECOLOGY. In: Bastian, O.; Steinhardt, U. (Orgs.) Development and perspectives of landscape ecology. Dordrecht: Kluwer Academic Publishers, 2002.

BUCCHERI FILHO, A. T; TONETTI, E. L.; Qualidade ambiental nas paisagens urbanizadas. In: Planejamento da Paisagem como subsídio para a participação popular no desenvolvimento urbano. Estudo aplicado ao bairro de Santa Felicidade Curitiba/PR. / Organização de João Carlos Nucci. Curitiba: LABS/DGEOG/UFPR, 2010, p. 14-25. Disponível em www.geografia.ufpr.br/laboratorios/labs/?pg=publicacoes-php. Acesso em 20/08/2013.

CAVALHEIRO, F. Urbanização e alterações ambientais. In.: SANTOS, D. G. Dos e NUCCI, J. C. (Orgs.). Paisagens Geográficas : um tributo a Felisberto Cavalheiro. Campo Mourão: Ed. da FECILCAM, 2009, p. 65-77.

CAVALHEIRO, F.; DEL PICCHIA, P.C.D. Áreas verdes: conceitos, objetivos e diretrizes para o planejamento. In: $1^{\circ}$ congresso brasileiro sobre arborização urbana $/ 4^{\circ}$ encontro nacional sobre arborização urbana, 4, 1992, Vitória. Anais I e II. 1992. $\quad$ p. 29-35. Disponível em http://www.geografia.ufpr.br/laboratorios/labs/arquivos/CAVALHEIRO\%20et\%20al\%2 0(1992).pdf. Acesso em 23/12/2011.

DANNI-OLIVEIRA, I. M. A cidade de Curitiba e a poluição do ar. In: Carlos Augusto F. Monteiro; Francisco Mendonça. (Orgs.). Clima Urbano. Ed. São Paulo: Contexto, 2003, v. 1, p. 155-174.

DETWYLER, T. R.; MARCUS, M. G. (orgs.). Urbanization and Environment . The Physical Geography of the City. Belmont (California): Duxbury Press. 1972. 
DI FIDIO, M. Architettura del paesaggio-criteri di pianificazione e construzione con numerosi schemi e illustrazioni . Milano, Pirola editore, 1985.

DIAS, G. F. Pegada ecológica e sustentabilidade humana: as dimensões humanas das alterações ambientais globais - um estudo de caso brasileiro. São Paulo: Gaia, 2002.

DOUGLAS, I. The urban environment. Londres: Edward Arnold (Pub.) Ltda., 1983.

ESTÊVEZ, L. F. Relatórios Ambientais Prévios (RAPs) realizados em Curitiba (PR): uma análise com base nos princípios do Planejamento da Paisagem. Tese de doutorado. Universidade Federal do Paraná. Programa de Pós-Graduação em Geografia, Curitiba, 2014.

FELLENBERG, G. Introdução aos problemas da poluição ambiental. São Paulo, EPU/SPRINGER/EDUSP, 1980.

GOMES OREA, D. O meio físico e o planejamento. Madri: CIFCA, 1978.

HOUGH, M. Naturaleza y ciudad: Planificación urbana y procesos ecológicos. Barcelona: Ed. Gustavo Gili, 1995.

JACKSON, L.E. The relationship of urban design to human health and condition. Landescape and Urban Planning. P. 191-200, 64, 2003.

JAMBOR, I. e SZILÁGYI, K. - Grünplanung im Rahmen der Stadtentwicklung. Garten + Landschaft , n. 7 p. 30-35.

KIEMSTEDT, H.; GUSTEDT, E. Landschaftsplanung als Instrument umfassender Umweltvor- soge ( Conferência Internacional ), 1990.

LLARDENT, L.R.A. Zonas verdes y espacios libres en la ciudad . Inst. de Estudios de Administración Local. Madri, 1982.

LOMBARDO, M.A. Ilha de calor nas metrópoles . O exemplo de São Paulo. São Paulo, Hucitec, 1985.

LÖTSCH, B. In search of human scale . Garten und Landschaft n. 6, 1984, ed. DGGL, Zeitschrift der Deutschen Gesellschaft für Garten kunst und Landschaftspflege.19-26.

McHARG, I. Design with Nature . New York. Back Edition, 1971.

McHARG, I. Proyectar com la naturaleza . Barcelona: Ed. Gustavo Gili, 2000.

MONTEIRO, C. A. F. - Qualidade ambiental - Recôncavo e Regiões limítrofes. Salvador, Centro de Estatísticas e Informações, 1987, 48p e 3 cartas. 
MONTEIRO, C. A. F. Geossistemas: a história de uma procura. São Paulo: Contexto, 2000.

$\mathrm{NUCCl}$, J. C. Qualidade ambiental e adensamento: um estudo de Planejamento da Paisagem do distrito de Santa Cecília (MSP). Tese de doutorado. Universidade de São Paulo. Programa de Pós-Graduação em Geografia Física. 1996.

NUCCl, J. C. Qualidade ambiental \& adensamento urbano. São Paulo: Humanitas/FAPESP, 2001.

NUCCl, J. C. Qualidade ambiental \& adensamento urbano. 2 a edição. Curitiba: Edição do Autor, 2008, 142 p. Disponível em http://www.geografia.ufpr.br/laboratorios/labs/arquivos/qldade_amb_aden_urbano.pd f. Acesso em 03/05/2010.

NUCCI, J. C.; CAVALHEIRO, F. Cobertura vegetal em áreas urbanas - conceito e método. Geousp, São Paulo, v. 6, n. 6, p. 29-36, 1999.

NUCCI, J. C.; KRÖKER, R.; SCHMIDT, E. ; BUCCHERI FILHO, A. T. Mapeamento da qualidade ambiental urbana. In: Environmental Challenges of Urbanization, 2005, Brasília. International Congress on Environmental Planning and Management Environmental Challenges of Urbanization. Brasília: Catholic University of Brasilia, 2005.

PLANETA SUSTENTÁVEL. Cidade dos sonhos. Disponível em http://planetasustentavel.abril.com.br/noticia/cidade/conteudo_283474.shtml?func=2 Acesso em 25/07/2013.

PUPPI, I.C. Estruturação sanitárias das cidades. CETESB, São Paulo. Ed. UFPR, sem data.

SANTOS, R.C.B. dos. Rochdale e Alphaville: formas diferenciadas de apropriação e ocupação da terra na metrópole paulistana. São Paulo. Tese de doutorado. DGFFLCH-USP, 1994, 277p.

SBAU - Sociedade Brasileira de Arborização Urbana. Carta de Londrina e lbiporã . Boletim Informativo, ano III, n. 5, março de 1996, Botucatu/SE.

SPIRN, A. W. O Jardim de Granito: A Natureza no Desenho da Cidad e . São Paulo, Editora da Universidade de São Paulo, 1995.

SUKOPP, H., KUNICK, W. Die Gross-Stadt als Gegenstand Okolagischer Forschung . Zeit der T.U. Beriin, Berlim, v. 5, p.710-716,1973.

SUKOPP, H. Urban Ecology - scientific and practical aspects. In: BREUSTE, J.; FELDMANN, H.; UHLMANN, O. (Eds.) Urban Ecology . Berlim: Springer, 1998.

SUKOPP, H.; WERNER, P. Naturaleza em las ciudades . Madri: MOPT, 1991. 
TONETTI, E. L. Potencialidades de adensamento populacional por verticalização das edificações e Qualidade Ambiental Urbana no Município de Paranaguá, Paraná, Brasil . Tese de doutorado. Universidade Federal do Paraná. Programa de PósGraduação em Geografia. 2011.

TRICART, J. Ecodinâmica. Fundação Instituto Brasileiro de Geografia e Estatística. Superintendência de Recursos Naturais e Meio Ambiente. Diretoria Técnica. Rio de janeiro, 1977.

TROPPMAIR, H. Biogeografia e meio ambiente. 6. Ed. Rio Claro: Divisa, 2004.

TUAN, Y. Espaço e lugar. Difel, 1977, 250p.

VALASKI, S. Avaliação da qualidade ambiental em condomínios residências horizontais com base nos princípios do planejamento da paisagem. Estudo de caso: bairro Santa Felicidade - Curitiba/PR . Dissertação (Mestrado) - Setor de Ciências da Terra, Universidade Federal do Paraná, Curitiba. 2008. Disponível em www.geografia.ufpr.br/laboratorios/labs/?pg=publicacoes-php. Acesso em 01/08/2013.

VALASKI, S. Estrutura e dinâmica da paisagem: subsídios para a participação popular no desenvolvimento urbano do município de Curitiba-PR. Tese de doutorado. Universidade Federal do Paraná. Programa de Pós-Graduação em Geografia, Curitiba, 2013.

ZORZAL, F.M.B.; DIESEL, A.; BORTOLI, P.S. de.; PEREIRA, L.C. Carta de Ruído da Cidade de Curitiba enquanto poluição sonora difusa. Engenharia e Construção , Curitiba, v., n.81, p.58-63, jun. 2003.

(Recebido em 02.09.2014; Aceito em: 22.07.2015) 